\title{
The Significance of Knowledge Management Systems at Financial Decision Making Process
}

\author{
Zainab Abdulshaheed Mohsen \\ College of Business and Finance, Ahlia University \\ P.O. Box 10878, 1st Floor Gosi Complex Exhibitions Road, Manama, Kingdom of Bahrain \\ Mai Ali \\ College of Business and Finance, Ahlia University \\ P.O. Box 10878, 1st Floor Gosi Complex Exhibitions Road, Manama, Kingdom of Bahrain
}

\author{
Akram Jalal \\ Management Information System Department \\ College of Business and Finance, Ahlia University \\ P.O. Box 10878, 1st Floor Gosi Complex Exhibitions Road, Manama, Kingdom of Bahrain \\ Tel: 973-3838-3411 E-mail: ajalal@ahliauniversity.edu.bh
}

Received: January 4, 2011 Accepted: March 22, $2011 \quad$ doi:10.5539/ijbm.v6n8p130

\begin{abstract}
Nowadays Knowledge management has been of great interest globally. Bahraini's Bank have been given interest to IT investment in knowledge Management. This paper concentrate on the availability of Knowledge-Based System and the benefits estimated from the use of such a system in increasing the effectiveness of decisions. The paper highlights the need for an automated tool to support the decision-making process. The affect of four factors, representing the use of KMS, had been studied to see their effect on decisions. These factors are: availability of required technologies, capabilities of individuals, coordination between departments, and acceptance and trust of decision makers.

Overall, the results show that there was a significant relationship between the effectiveness of decision making and the availability of required technologies, capabilities of individuals and coordination between departments. On the other hand, there was no relationship between the effectiveness of decision making and acceptance and trust of decision makers in Bahraini banks.
\end{abstract}

Keywords: Knowledge Management System, Decision making, Banks

\section{Introduction}

Today the usage of information and knowledge has increased in all types of organizations in order to simplify all the activities and enhance the decisions making process.

The importance of managing the organizations' information and knowledge becomes a vital role that encourages the company's entire manager to invest more money, times and effort to manage such information and knowledge.

Knowledge management is an organization strategic effort that used to capture information and experience of employees and customers which is stored in database, paper or in peoples' intellect then distributes this knowledge to gain more benefit.

Knowledge management consists of several steps that allow the flows of knowledge among all interest users in the organization. The first step is knowledge creation that means the entering of the knowledge in the system . Second step is maintains the knowledge by remaining it in the system which is refer to Knowledge Retention, the flow of knowledge from one part to another within the system (Knowledge Transfer) and finally implementing the knowledge in the organization decision making and any business process which is refers to Knowledge utilization.

These whole processes of capturing, storing and distributing knowledge in the entire organization help employees work smarter, minimize duplication, and deliver more innovative products and services that meet the customers' requirements. From business point of view, knowledge management affects the whole organization by helping employees, managers, and executives share information and best practices that positively impact 
collective performance. Knowledge management is a value-added technique that aims to maximize profits, innovation, and decision making by share better information and knowledge between every member working within the organization.

Knowledge can be classified into three main categories: explicit knowledge, implicit knowledge and tacit knowledge. Explicit knowledge can be transferred easily through books and reports so it's a tangible form of knowledge. Implicit knowledge, is not explicitly captured, but can be simply reported explicitly in to papers such as the working experience. Tacit knowledge is an intangible form of knowledge such as values and beliefs. For the organization the tacit knowledge is the most important type so it is rarely recorded and transferred.

Knowledge management is becoming very important in almost all Banks since it simplifies the delivery of timely and effective information that are used in all the organization's processes from planning, controlling, decision making and evaluation. It helps managers in formulating strategic, tactical and operational activities in a best ways in order to achieve the organization's desired objectives.

Nowadays Modern banks investigate the importance of the value of knowledge Management in the banks business practices. The knowledge covers the range from the bank organizations' own internal intellectual capital, to the wealth of data heel on any customer's transaction. (Jayasundara, 2008)

The banking sector is always targeted to improve their customer satisfaction that will result in revenue increasing. The process of Knowledge creation, storage and dispersion becomes essential and banks assign specialized personnel to watch over and manage these critical processes.

The most common fields of knowledge management applications in a bank are risk management, marketing management, customer relationship management and performance measurement especially for the benefit of its stakeholders. Usually, in major banks investments in Knowledge Management systems such as Decision Support Systems, Data Warehouses and Data Mining are rapidly growing. (Jayasundara, 2008)

Nowadays, bank managers use computerized support system as a personal support in decisions making. Knowledge Management System in banks ensures better and more efficient results in decision making.

The aim of this paper is to examine the impact of Knowledge Management System in supporting decision making process in the Bahrainis' Banks by highlighting the importance of KMS in banking sector and the importance of knowledge management integration and the role it plays in helping knowledge workers making effective and just-in-time decisions. The main research objectives can be summarized in these two points:

1) To examine the value of KMS in supporting decision making process.

2) To develop a contextual profile of use of KMS, including the Availability of required technologies (Hardware and software) individuals' capabilities and awareness in using KMS, department coordination, decision maker acceptance and trust of the system.

This paper is organized as follows:

Section 1: Introduction: contains an overview of the whole research, it begins with a general information about knowledge management and then moves to focus on how KMS used in banks and the main role it plays .

Section 2: Literature Review: Shows different existing studies related to this research.

Section 3: Methodology: Describes the method of research used in this study, and specify the main factors that will be used in this study followed by the research questions, hypothesis and research design.

Section 4: Challenges: Specify the current problem and the difficulties that organizations face in making decisions and how KMS can simplify and improve the decision making process.

Section 5: Data Analysis and Results: The data that was collected from the questionnaire and entered into the SPSS software for advance statistical analysis then commenting on the SPSS result and specifying the main essential factors that affect and enhance the efficiencies of decision making.

Section 6: Discussion: This section discusses the final results, and test the research hypothesis and comparing this result with previous researcher result.

Section 7: Conclusion and Recommendations: Presents the research conclusions and recommendation.

\section{Literature Review}

Many authors and researchers define KM in several ways. In general term, Liebowitz (2000) defined KM as the process of creating value from an organization's tangible assets .

Siemieniuch and Sinclair (2004) obviously defined Knowledge Management as a pillar in the seven bases of organizational effectiveness; Thus KM can lead to many organizational benefits like better problem solving and decision making, improved customer services, increasing profits, better stuff attraction, more innovation and greater creativity.

KM helps organizations find, select, organize, disseminate, and transfer important information and expertise necessary for activities such as problem solving, dynamic learning, strategic planning and decision-making (Gupta et al., 2000). Other mentioned the main key components of successful KM S. Drew (1999) which 
determined that culture, technology, organization, and people as the main key components.

In simple words KM consist of a range of strategies and practices used in an organization to identify, create, represent, distribute, and enable adoption and shares of knowledge, either embodied in individuals or embedded in organizational processes or practice.

$\mathrm{KM}$ is a fast-moving field created by the collision of several others, including human resources, organizational development, change management, IT, brand and reputation management, performance measurement, and evaluation (Bukowitz, Williams, 2002).

Zhenfeng Chen (2010) recognized two main categories of Knowledge: explicit knowledge and tacit knowledge. According to the British philosopher Michael Polanyi, explicit knowledge mainly refers to the structure knowledge expressed by text, images and symbols, which can be taught verbally and learned by textbooks, reference materials, databases, etc. Tacit knowledge only exists in people's minds, which is difficult to express by words, symbols, images media. The management of explicit knowledge is relatively easy; you can use information systems, such as code and database to set knowledge base. The explicit knowledge is achieved through teaching, training. Its sharing depends on electronic information systems. The explicit knowledge is the basis for innovation. But the management of tacit knowledge is relatively more difficult. Tacit knowledge contains many knowledge cheats such as the work of know-how, experience, perspective and values, which implies more innovative ideas. These are the essence of the core competitiveness.

Many technologies and products can be used to support KM. Based on the purposes they serve they can be classified in one or more of the following categories: business intelligence, collaboration, content and document management, e-learning, knowledge base, portals, customer relationship management, data mining, workflow, and search. (Serban, Luan, 2002).

Other demonstrate that knowledge management systems (KMSs) are one of the most effective methods of managing, formalizing and automating knowledge in organizations, such as banks if they are applied in appropriate areas and to appropriate tasks. A KMS usually captures and organizes knowledge, thus increasing productivity by reducing the time taken to perform a problem solving task (Kingston, 2004).

Moreover, a survey by Reuters found that 90 percent of companies that deploy a KM solution benefit from better decision making, and 81 percent say that they notice increase productivity (Malhotra, 2001). These surveys focused on showing exactly how KM is substantial for decision making. Thus, it is not surprising that many organizations have invested significant amounts of time and money in KM initiatives over the last few years (Walsham, 2001).

In finding ways to work with knowledge as an asset, banks and organizations are transforming knowledge from an abstract concept to an increasingly tangible and manageable one (Serban, Luan, 2002).

KMSs play a major role in support decision-making in banks and IT without suitable KM exercise would be do-nothing. The employees who cooperate or perform tasks together share only partially overlapping goals; individual group member's activities must be coordinated to ensure that the disparate individuals come to share the same goals (Shim et al., 2002). With KM, banks achieve efficiencies, ensure competitive advantage, and spur innovation (Serban, Luan, 2002).

In modem banks there is no debate about the value of Knowledge Management as a business practice. Banks and all other players in the competitive financial service sector have recognized that knowledge is power (Sorrentino, 1999). The knowledge covers the range from the bank organizations' own internal intellectual capital, to the wealth of data heel on any customer's transaction. (Jayasundara, 2008)

The overall aim of the banking sector is to enhance their customer satisfaction and increase revenue as a result, thus skill at knowledge management has become a critical competency for banking sector survival in the 2lst centaury. Also it becomes essential to assign a person or persons to watch over and manage the creation, storage and dispersion of knowledge (Sorrentino, 1999). These personnel should also be responsible for the creation and implementation of strategy that generates value from organizational knowledge. (Jayasundara, 2008)

Vencatachellum and Jeetah (2008) concentrated on the state of Knowledge management among the commercial banks in Mauritius, their study indicated that a majority of respondents $(70 \%)$ claimed they were familiar with the KM term but $60 \%$ of them did not give a valid KM definition. Moreover, all the banks had a formal strategy, and consider it important for achieving organizational effectiveness, but only $30 \%$ had a formal KM strategy. Whereas Widen-Wulff and Suomi (2003) focused on the insurance sector and studied the knowledge management practices of 15 Finnish insurance companies of different sizes and product portfolios. Their analysis showed that effective knowledge sharing has a positive correlation to business success.

Others focused on the many reasons behind why bank employees don't share knowledge. L. Vaas (1999) states that sometimes employees are willing to share but there is not enough time to do so, there is no skill in KM techniques, they do not understand $\mathrm{KM}$ and its benefits, there is lack of appropriate technology, there is no commitment from senior managers, there is no funding for KM, and the culture does not encourage knowledge sharing. Unless the organizational environment rewards knowledge sharing, the entire effort to institutionalize a 
KM system will fail. (Serban, Luan, 2002).

It can be concluded that KMS help banks ensure better and more efficient results in decision-making and the banks top management has to give their employees all appropriate and suitable technologies to share knowledge . Furthermore, they have offer the appropriate atmosphere for using KMS and encourage their employees to share knowledge. So, KMS is support and assist the coordination, communication, content sharing between all banks employees.

Shannak Rifat (2010) states that group of factors representing the effectiveness of Knowledge Management System within the organization were studied. These factors that cover all organizational levels include:

1) Availability of required technologies (Hardware and software)

2) Experts people :are the users' capabilities and awareness handlings of technologies and information.

3) Coordination and communication between employees at different levels within different department.

4) Decision makers trust of the system and information that contains.

\section{Methodology}

This study is concerned in the role that Knowledge Management System plays in supporting decision makers in financial organizations (Banks). Moreover, it uses the explanatory (empirical) method to quantify the knowledge sources that may be used in decision-making process.

Several factors that affect the use of knowledge Management System in the decision making process were studied. These factors include: availability of required information technologies, Individuals' capabilities and awareness, coordination between departments, acceptance and trust of decision makers. The relationship between these factors and the decision making process is illustrated in the figure 1.

\section{[Insert Figure 1 here]}

\subsection{Research Questions and hypothesis}

The main objective of the research study is to investigate the following questions:

1) To what extent Knowledge Management System is affecting the Decision making process within the organization?

2) Whether the Banks in Bahrain using Knowledge Management System to support decision making process?

This study aim to answer some other questions concerning the research factors and their relationships as following:

1) How is the availability of required information technologies affect the decision making process?

2) How is the Individuals' capabilities and awareness affect the decision making process?

3) Is their any statistical relationship between coordination between departments of the bank and the effectiveness of the decision making process?

4) Is their any statistical relationship between Acceptance and trust of the system of decision maker and the decision making process?

To examine the impact of Knowledge Management System on the quality of decision making process, the following hypothesis was tested.

Hypothesis 1. whether, technologies (hardware and software) have a significant relationship with the effectiveness of decision making.

$\mathrm{H}_{0}$ : There is no significant relationship between technologies and effectiveness of decision making

$\mathrm{H}_{1}$ : There is a significant relationship between technologies and the effectiveness of decision making

Hypothesis 2. Whether, expert people have a significant relationship with effectiveness of decision making.

$\mathrm{H}_{0}$ : There is no significant relationship between expert people and effectiveness of decision making

$\mathrm{H}_{1}$ : There is a significant relationship between expert people and effectiveness of decision making

Hypothesis 3. Whether, department coordination has a significant relationship with effectiveness of decision making.

$\mathrm{H}_{0}$ : There is no significant relationship between department coordination and effectiveness of decision making

$\mathrm{H}_{1}$ : There is a significant relationship between department coordination and effectiveness of decision making

Hypothesis 4. Whether, decision makers' acceptance and trust of the system has a significant relationship with effectiveness of decision making.

$\mathrm{H}_{0}$ : There is no significant relationship between decision maker acceptance and trust of the system and decision making

$\mathrm{H}_{1}$ : There is a significant relationship between decision maker acceptance and trust of the system and decision making. 


\subsection{Research Design}

The research population of the study includes employees work in Bahraini's Banks. Ideally, to answer our questions we used quantitative method for the study. The questionnaire includes two types of questions general questions and variables questions. Data was collected via 70 questionnaires distributed to 3 leader commercial banks in the kingdom of Bahrain. Those banks are Ahli United bank, Bahrain Islamic Bank and ARCapita Bank. It included data and items needed to examine the value of Knowledge in supporting decision making process.

\section{Challenges}

Knowledge Management System has an important role to play in banks and financial organizations. Some banks have already adopted KMS, but others have been slower to take up KMS practices. KMS strategies and techniques are not exclusively applicable to large banks; they can be valuable in all banks and financial institutions.

The first issue concerning the staff is a lack of communication at different levels. One of the most important uses of KMS is facilitating effective communication. For people within a bank to be able to share knowledge effectively, there must be suitable methods of communication available as well as a supportive culture. While Banks have a culture that supports communication, it is significantly tending towards verbal informal communication methods. The term verbal is denoted what are considered "face-to-face" methods of knowledge sharing. Keong \& Al-Hawamdeh (2002) further categorize "face to face" communication channels as either mediated or unmediated by technology. Unmediated face-to-face methods include meetings, presentations, discussions, and mediated methods include telephone, e-mail, and groupware.

The most preferred channels in banks are unmediated, such as meetings. Unfortunately, although the banks' employees prefer informal, face-to-face communication, the reality of modern lifestyles has made these methods of communication less practical and time consumed and not an effective way of communication. The staff has very busy schedules that make the discussion difficult. This is the main downside of face-to-face channels that are unmediated by technology: they require a lot of time and location. E-mail is also used, but while this channel does not have the restriction of requiring a specific time or place it does wasted time in terms of going and receiving messaging, especially when dealing with more than one individual. Essentially, reliance on informal verbal methods have caused some problems, that not everybody gets information in a timely fashion or not getting information at all if they were not attending the discussion.

The challenge in attempting to fill these gaps is finding ways to improve the effectiveness and efficiency of communication without excessively disrupting their culture or overloading them with IT. The point is not to remove their existing methods of communication, since solutions must match their existing practices and fit within their culture. In this case, the recommendation is to generate another mediated face-to-face channel as an online room for discussions. There are currently many other sources, easy to manage technologies that offer options for discussion and document sharing. The advantage of these online environments is that they allow for multiple people to discuss and work on documents without being in the same place at the same time. Also, discussion and sharing of documents permit all users to see the responses simultaneously.

Using KMS can provide templates which are an excellent way to achieve this. Once templates are used for existing documentation activities, they can then be extended to other activities that would benefit from knowledge capture. This knowledge can then be transferred to the next generation. Examining past decisions and actions can improve decision-making in the present

Bank can move ahead and becoming an example of an organization that has successfully adapted some of the KMS strategies and tools.

\section{Data Analysis \& Results}

For the research analysis, the SPSS analysis system is used. Different tests are applied to the collected data like: one sample T-test, frequency tables and regression ANOVA. The questions in the questionnaire are scaled from 1 to 5.1 represent the lower end (strongly disagree) and 5 represent the upper end (strongly agree). The results of the questions have been inputted in the SPSS. Each two questions represent one factor (independent variable), last two questions represent the dependent variable as follow:

1) Q1\&2 measure the first independent factor: the availability of information technology (HW \& SW)

2) Q3\&4 measure the second independent factor: capabilities and individual awareness

3) Q5\&6 measure the third independent factor: coordination between department

4) Q7\&8 measure the fourth independent factor: acceptance and trust of decision maker

5) Q9\&10 measure the dependent factor: effectiveness of decision making.

In order to get more accurate results, mean function is applied to each variable questions resulting in five new columns H1 (Q1\&2), H2 (Q3\&4), H3 (Q5\&6), H4 (Q7\&8) and Decision Making (Q9\&10). All the following tests will be applied to the average results (H1, H2, H3, H4 \& Decision Making).

Hypothesis 1: Availability of technology ( $H W \& S W)$ 


\section{[Insert Table 1 here]}

Table 1 show that the average investment in information technology to support decision making in Bahraini's banks is 3.49 which is at the upper end of the scale indicated in the questionnaire (1-5). This shows that the Bahraini banks invest a reasonable amount in information technology.

\section{[Insert Table 2 here]}

We can see from table 2 that information technology is a supported factor to the overall research. From the T test analysis, $\mathrm{P}$ value is .000 which is less than .05 and $\mathrm{t}$ value is 6.82 which is more than 1.65.

\section{[Insert Table 3 here]}

From the regression ANOVA table, $\mathrm{P}$ Value is .000 which is less than the critical value .05 and $\mathrm{F}$ value is greater than 1.9. So, we reject the null hypothesis $(\mathrm{H} 0)$ and accept the alternative $(\mathrm{H} 1)$.

It seems that there is a highly significant relationship between availability of technology and the effectiveness of decision making.

$\mathrm{R}$ square is .592 , this mean that $59.2 \%$ of the variation in the dependent variable (Decision making effectiveness) is explained by the variation in the independent variable (Availability of technology (HW \& SW)).

Table 4 shows that $34.3 \%$ of the banks employee selects 3.5 which are slightly more than adequate from the scale defined in the questionnaire. This indicates that respondents believe that the investment in information technology to support decision making in Bahraini's banks is slightly more than adequate.

\section{[Insert Table 4 here]}

\section{Hypothesis 2: Capabilities and individual awareness}

\section{[Insert Table 5 here]}

Table 5 shows that the mean for supporting an advance training using a computer based information technology to support the decision making in Bahraini's banks is 3.49 which is at the upper end of the scale indicated in the questionnaire (1-5). This shows that Bahraini banks adequately support any advance training in information technology to enhance the decision making by the expert people.

\section{[Insert Table 6 here]}

We can see from table 6 that individual capabilities and awareness is a supported factor to the overall research. From the T test analysis, $\mathrm{P}$ value is .000 which is less than .05 and $\mathrm{t}$ value is 6.56 which is more than 1.65.

\section{[Insert Table 7 here]}

From the regression coefficient table 1, P Value is .000 which is less than the critical value .05 and $\mathrm{F}$ value is greater than 1.9. So, we reject the null hypothesis (H0) and accept the alternative (H1).

It seems that there is a significant relationship between individual capabilities and awareness and the effectiveness of decision making.

$\mathrm{R}$ square is .599 this mean that $59.9 \%$ of the variation in the dependent variable (Decision making effectiveness) is explained by the variation in the independent variable (Capabilities and individual awareness).

Table 8 shows that $32.9 \%$ of the banks employees select 3.5 which are slightly more than adequate from the scale defined in the questionnaire. This indicate that respondents believe that the Bahraini banks adequately support any advance training in information technology to enhance the decision making by the expert people.

\section{[Insert Table 8 here]}

\section{Hypothesis 3: Coordination between departments}

\section{[Insert Table 9 here]}

Table 9 demonstrates that the mean for information generated by KMS and coordination between different departments is 3.38 which is at the upper end of the scale indicated in the questionnaire (1-5). This shows that Bahraini banks believe that information generation and coordination between departments enhance the decision making.

\section{[Insert Table 10 here]}

We can see from table 10 that coordination between departments is a supported factor to the overall research. From the T test analysis, $\mathrm{P}$ value is .000 which is less than .05 and $\mathrm{t}$ value is 4.79 which is more than 1.65 .

\section{[Insert Table 11 here]}

From the regression coefficient table 1, P Value is .000 which is less than the critical value .05 and $\mathrm{F}$ value is greater than 1.9. So, we reject the null hypothesis (H0) and accept the alternative (H1).

It seems that there is a significant relationship between coordination between departments and the effectiveness of decision making. 
$\mathrm{R}$ square is .728 this mean that $72.8 \%$ of the variation in the dependent variable (Decision making effectiveness) is explained by the variation in the independent variable (Coordination between departments).

Table 12 shows that $28.6 \%$ of the banks employee select 3.00 which is between neutral and agree from the scale defined in the questionnaire. This indicates that respondents believe that information generation and coordination between departments enhance the decision making.

\section{[Insert Table 12 here]}

\section{Hypothesis 4: Acceptance and trust of decision maker}

\section{[Insert Table 13 here]}

Table 13 illustrates that the mean for confidence and trust of users regarding the information generated by KMS to support the decision making in Bahraini's banks is 2.55 which is at the low end of the scale indicated in the questionnaire (1-5). This shows that Bahraini banks are not highly confident and trust with the information generated by KMS to enhance the decision making.

\section{[Insert Table 14 here]}

We can observe from table 14 that acceptance and trust is not a supported factor to the overall research. From the $\mathrm{T}$ test analysis, $\mathrm{t}$ value is -6.58 which less than 1.65 is.

\section{[Insert Table 15 here]}

From the regression coefficient table, $\mathrm{P}$ Value is .226 which is greater than the critical value .05 and $\mathrm{F}$ value is 1.49 which is less than 1.9. So, we fail to reject the null hypothesis (H0) and reject the alternative (H1).

It seems that there is no significant relationship between decision maker acceptance and trust and the effectiveness of decision making.

$\mathrm{R}$ square is .021 this mean that $2.1 \%$ of the variation in the dependent variable (Decision making effectiveness) is explained by the variation in the independent variable (Acceptance and trust of decision maker). Which means that there is no impact of the trust of decision maker on the effectiveness decision making.

Table 16 shows that $54.3 \%$ of the banks employee select 3.00 and below which indicate that they are not much trust of the information generated by KMS.

\section{[Insert Table 16 here]}

Dependent variable: Decision making

\section{[Insert Table 17 here]}

Table 17 illustrates that the mean for accurate decision making resulting from information generated by KMS in shortest time is 3.5 which is at the upper of the scale indicated in the questionnaire (1-5). This shows that Bahraini banks are using KMS to generate accurate decisions in shortest time.

\section{[Insert Table 18 here]}

We can observe from table 18 that accuracy of decision making by using KMS is a supported factor to the overall research. From the T test analysis, $\mathrm{P}$ value is .000 which is less than .05 and $\mathrm{t}$ value is 6.45 which is more than 1.65 .

Table 19 shows that $35.7 \%$ of the banks employees select 3.50. This indicates that respondents consider that Bahraini banks are using KMS to generate accurate decisions in shortest time.

\section{[Insert Table 19 here]}

\section{Discussion}

The statistical analysis of the questionnaire demonstrates that the majority of the questions has tendency to the agreement; except for specific questions.

The regression results from the Bahraini banks data seem that the first three independent variables (availability of IT, coordination between department \& capabilities \& individual awareness) have a significant relationship with the dependent variable (decision making). We can say that there is a good fit between the data and the assumed regression model. While the last independent variable (acceptance \& trust of decision maker) has no significant relationship with the dependent variable (decision making). For the first three independent variables it is noticed that $\mathrm{F}$ value is large which indicate that the relationship between these variables and the dependent variable is very strong and the decision making is highly dependent and correlated to these independent variables.

From the previous analysis, it has been founded that investment in information technology is an essential factor to support the decision making in Bahrainis' banks. This finding is in proportion to Walsham which stated that "it is not surprising that many organizations have invested significant amounts of time and money in KM initiatives over the last few years".

Another finding is that information generation and coordination between departments are highly enhancing the decision making. This finding is in contrary to Serban and Luan which stated that "sometimes employees are 
willing to share but there is not enough time to do so, there is no skill in KM techniques, they do not understand $\mathrm{KM}$ and its benefits, there is lack of appropriate technology, there is no commitment from senior managers, there is no funding for $\mathrm{KM}$, and the culture does not encourage knowledge sharing".

However, Shim et al. declared that "KMSs play a major role in support decision-making in banks and IT without suitable KM exercise would be do-nothing. The employees who cooperate or perform tasks together share only partially overlapping goals; individual group member's activities must be coordinated to ensure that the disparate individuals come to share the same goals". This is compatible with the previous finding about the importance of coordination between departments to improve the decision making.

One of the earlier research stated that "The overall aim of the banking sector is to enhance their customer satisfaction and increase revenue as a result, thus skill at knowledge management has become a critical competency for banking sector survival in the 21 st centaury. Also it becomes essential to assign a person or persons to watch over and manage the creation, storage and dispersion of knowledge (Sorrentino, 1999). These personnel should also be responsible for the creation and implementation of strategy that generates value from organizational knowledge. (Jayasundara, 2008).

This opinion is in line with the result founded in this research that concludes individual's capabilities and awareness are important in enhancing the decision making processes.

Finally, the negative tendency in answers the questions concerned with acceptance and trust of decision maker return to their fear that the information provided by KMS is not sufficient enough to make an effective decisions. They think that there are other important elements to enhance their decisions such as experience.

Bank employees especially at high managerial levels within the sample of the research prefer to depend on their own intuition in deciding the strategy of the organization's future, and prefer not to share the knowledge they have with others.

\section{[Insert Table 20 here]}

As illustrated in table 20, the combined relationship between the dependent variable and the overall independent variables are highly significant. The significant value is .000 which is less than the critical value .05 and $\mathrm{F}$ value is 84.52 .

From the coefficient table, the overall model confirmed the result reached from the data analysis section. The significant values of $\mathrm{H} 1, \mathrm{H} 2$ and $\mathrm{H} 3$ are less than .05. However, the significant value of $\mathrm{H} 4$ is more than .05 as concluded previously.

\section{Conclusion and Recommendations}

Based on the results and analysis of the questionnaire it is concluded that:

1) The availability of Knowledge management technique can be of great benefit in the practice of bank development through improving the efficiency of different operating activities.

2) Banks in Bahrain had shown an adequate percentage of spending over information technology projects, MIS, and knowledge management projects.

3) There has been unexpectedly less interest in a system through which knowledge and work experience may be retrieved.

4) As a result of importance of employees' capabilities and awareness in enhancing the decision making, there has been a significant interest in a system that includes information with easy retrieval process.

5) Acceptance and trust of decision makers in the knowledge, information, and opinion they provide represent a main part in the success of KMS.

According to the previous presented results and conclusions, it is recommended the following:

1) More expenditure should be allocated by organizations for the improvement of MIS and KM projects.

2) A continuous educating of banks employees of the importance of Knowledge Management and the benefits related to it.

3) Workshops, seminars, training courses, and training sessions should be prepared to increase awareness for KM.

4) To discuss the achievements of each department resulting from using KMS, the banks should held annual meeting to build future strategy based on the previous achievement.

\section{References}

Bukowitz, W. R., \& Williams, R. L. (2002). The Knowledge Management Field. Book - Upper Saddle River, N. J.: Financial Times, Prentice Hall.

Drew, S. (1999). Building Knowledge Management into Strategy: Making Sense of a New Perspective, Strategy at the Leading Edge. New Research \& Conference Reports, Long Range Planning, Vol. 32, Iss 1.

Gupta, B., Iyer, L., \& Aronson, J. E. (2000). Knowledge Management: A Taxonomy, Practices and Challenges. 
Industrial Management and Data Systems, Vol. 100, Iss.1, 2.

Jayasundara, Chaminda Chiran. (2008). Knowledge Management in Banking Industries: uses and opportunities. Journal of the University Librarians Association of Sri Lanka, Vol. 12, PP.68-79.

Keong Lee, Chu and Suliman Al-Hawamdeh. (2002). Factors Impacting Knowledge Sharing. Journal of Information \& Knowledge Management, Vol. 1 Iss.1, PP.49-56.

Kingston, J. (2004). Conducting Feasibility Studies for Knowledge Based Systems. - Knowledge Based Systems. [Online] Available: www.sciencedirect. com.

Liebowitz, J. (2000). Building organizational intelligence: a knowledge management primer. FL: CRC Press

Luan, J., \& Serban, A. M. (2002). Technologies, Products, and Models Supporting Knowledge Management. New Directions for Institutional Research, Iss. 113.

Malhotra, Y. (2001). Expert Systems for Knowledge Management: Crossing the Chasm between Information Processing and Sense Making. Expert Systems with Applications, 20.

Muhammad Shaukat \& Muhammad Zafarullah. (2009). Impact of Information Technology on Organizational Performance: An Analysis of Qualitative Performance Indicators of Pakistan's Banking and Manufacturing Companies. Eurpoean Journal of Economics, Finance and Administrative Sciences, Iss. 16

Murray E.Jennex, Stefan Smolnik \& David Croasdell. (2008). Towards Measuring Knowledge Management Success.

Serban, M. A., \& Luan, J. (2002). Overview of Knowledge Management. New Directions for Institutional Research, Iss. 113.

Shannak Rifat. (2009). Measuring Knowledge Management Performance. European Journal of Scientific Research, Vol. 35, Iss.2, PP.242-253.

Shannak Riffat. (1994). The effect of Managerial Information Systems on the performance of the public share holding companies in Jordan, Unpublished M.Sc. Thesis, University of Jordan.

Shannak Riffat. (2010). Knowledge-based Systems Support for Strategic Decisions.

Sher, Peter and Lee, Vivid. (2004). Information technology as a facilitator for enhancing dynamic capabilities through knowledge management. Information \& Management, Vol. 41, Iss. 8, PP. 933-945.

Shim, J. P., Warkentin, M., Coutney, J. F., Power, D. J., Sharda, R., \& Carlsson, C. (2002). Past, Present, and Future of Decision Support Technology. Decision Support Systems, 33.

Sorrentino, Maddalena. (1999). Notes on Knowledge Management in Banking, In KIO Meeting, Barcelona: Spain. [Online] Available: http://www.sistemi- informativi.org/kio/cons/ KIOme\&BarRTF. htm

Stephanie A. Lemieux \& Kimiz Dalkir. (1999). The Challenges of Applying KM in a Non-traditional Setting: the Case of a Nonprofit, Artistic Organization Vaas, L. (1999). Brain storming. PC Week, Vol.16, Iss. 22.

Walsham, G. (2001). Knowledge Management: The Benefits and Limitations of Computer Systems. European Management Journal, Vol. 19, Iss. 6.

Zikmund William. (2000). Business Research Methods, 6th Edition. The Dryden Press, Harcourt College Publisher, USA

Table 1. The one sample statistic of the first hypothesis

\section{One-Sample Statistics}

\begin{tabular}{|l|l|l|l|l|}
\hline & $\mathrm{N}$ & Mean & Std. Deviation & Std. Error Mean \\
\hline $\mathrm{H} 1$ & 70 & 3.4857 & .59571 & .07120 \\
\hline
\end{tabular}

Table 2. The one sample test of the first hypothesis

One-Sample Test

\begin{tabular}{|c|c|c|c|c|c|c|}
\hline & \multicolumn{9}{|c|}{ Test Value=3 } \\
\hline & $\mathrm{t}$ & $\mathrm{df}$ & Std. (2-tailed) & Mean Difference & 95\% Confidence Interval of the Difference \\
\cline { 5 - 7 } & & & & & Lower & Upper \\
\hline H1 & 6.822 & 69 & .000 & .48571 & .3437 & .6278 \\
\hline
\end{tabular}


Table 3. The frequency of $\mathrm{H} 1$

\begin{tabular}{|l|l|l|l|l|}
\hline Model & R & R Square & Adjusted R Square & Std. Error of the Estimate \\
\hline 1 & $.769^{\text {a }}$ & .592 & .586 & .41722 \\
\hline
\end{tabular}

ANOVA $^{\mathrm{b}}$

\begin{tabular}{|l|l|l|l|l|l|l|}
\hline Model & & Sum of Squares & df & Mean Square & F & Sig \\
\hline 1 & Regression & 17.163 & 1 & 17.163 & 98.597 & $.000^{\mathrm{a}}$ \\
\hline & Residual & 11.837 & 68 & .174 & & \\
\hline & Total & 29.000 & 69 & & & \\
\hline
\end{tabular}

a. Predictors: (Constant), H1

b. Dependent Variable: Decision Making

Table 4. Scale defined in the questionnaire of $\mathrm{H1}$

\begin{tabular}{|c|c|c|c|c|c|}
\hline \multicolumn{6}{|c|}{ H1 } \\
\hline & & Frequency & Percent & Valid Percent & Cumulative Percent \\
\hline \multirow[t]{7}{*}{ Valid } & 2.00 & 2 & 2.9 & 2.9 & 2.9 \\
\hline & 2.50 & 4 & 5.7 & 5.7 & 8.6 \\
\hline & 3.00 & 18 & 25.7 & 25.7 & 34.3 \\
\hline & 3.50 & 24 & 34.3 & 34.3 & 68.6 \\
\hline & 4.00 & 14 & 20.0 & 20.0 & 88.6 \\
\hline & 4.50 & 8 & 11.4 & 11.4 & 100.0 \\
\hline & Total & 70 & 100.0 & 100.0 & \\
\hline
\end{tabular}

Table 5. The one sample statistic of the second hypothesis

One-Sample Statistics

\begin{tabular}{|l|l|l|l|l|}
\hline & N & Mean & Std. Deviation & Std. Error Mean \\
\hline H2 & 70 & 3.4929 & .62839 & .07511 \\
\hline
\end{tabular}

Table 6 . The one sample test of the second hypothesis

One-Sample Test

\begin{tabular}{|l|l|l|l|l|l|l|}
\hline \multirow{2}{*}{} & \multicolumn{6}{|l|}{ Test Value $=3$} \\
\cline { 6 - 7 } & $\mathrm{t}$ & $\mathrm{df}$ & Sig.(2-tailed) & $\begin{array}{l}\text { Mean } \\
\text { Difference }\end{array}$ & 95\%Confidence Interval of the Difference \\
\cline { 5 - 7 } & & & & Lower & Upper \\
\hline H2 & 6.562 & 69 & .000 & .49286 & .3430 & .6427 \\
\hline
\end{tabular}

Table 7. The frequency of $\mathrm{H} 2$

Model Summary

\begin{tabular}{|c|c|c|c|c|}
\hline Model & $\mathrm{R}$ & R Square & Adjusted R Square & Std. Error of the Estimate \\
\hline 1 & $.774^{\mathrm{a}}$ & .599 & .593 & .41369 \\
\hline \multicolumn{5}{|c|}{ a. Predictors: (Constant), H2 } \\
\hline
\end{tabular}

Table 8. Scale defined in the questionnaire of $\mathrm{H} 2$

ANOVA

\begin{tabular}{|ll|r|r|r|r|r|}
\hline Model & & \multicolumn{1}{|c|}{$\begin{array}{c}\text { Sum of } \\
\text { Squares }\end{array}$} & df & Mean Square & \multicolumn{1}{c|}{$\mathrm{F}$} & Sig. \\
\hline 1 & Regression & 17.362 & 1 & 17.362 & 101.450 & $.000^{\mathrm{a}}$ \\
& Residual & 11.638 & 68 & .171 & & \\
& Total & 29.000 & 69 & & & \\
\hline
\end{tabular}

a. Predictors: (Constant), $\mathrm{H} 2$

b. Dependent Variable: DecisionMaking 
H2

\begin{tabular}{|ll|r|r|r|r|}
\hline & & Frequency & Percent & Valid Percent & $\begin{array}{c}\text { Cumulative } \\
\text { Percent }\end{array}$ \\
\hline Valid & 1.50 & 1 & 1.4 & 1.4 & 1.4 \\
& 2.00 & 1 & 1.4 & 1.4 & 2.9 \\
& 2.50 & 5 & 7.1 & 7.1 & 10.0 \\
3.00 & 16 & 22.9 & 22.9 & 32.9 \\
3.50 & 23 & 32.9 & 32.9 & 65.7 \\
4.00 & 16 & 22.9 & 22.9 & 88.6 \\
4.50 & 8 & 11.4 & 11.4 & 100.0 \\
& Total & 70 & 100.0 & 100.0 & \\
\hline
\end{tabular}

Table 9. The one sample statistic of the third hypothesis

One-Sample Statistics

\begin{tabular}{|l|l|l|l|l|}
\hline & $\mathrm{N}$ & Mean & Std. Deviation & Std. Error Mean \\
\hline $\mathrm{H} 3$ & 70 & 3.3786 & .66177 & .07910 \\
\hline
\end{tabular}

Table 10. The one sample test of the third hypothesis

One-Sample Test

\begin{tabular}{|c|c|c|c|c|c|c|}
\hline & \multicolumn{6}{|c|}{ Test Value $=3$} \\
\hline & \multirow[b]{2}{*}{$\mathrm{t}$} & \multirow[b]{2}{*}{ df } & \multirow[b]{2}{*}{ Sig. (2-tailed) } & \multirow{2}{*}{$\begin{array}{c}\text { Mean } \\
\text { Difference }\end{array}$} & \multicolumn{2}{|c|}{$\begin{array}{c}95 \% \text { Confidence Interval } \\
\text { of the Difference }\end{array}$} \\
\hline & & & & & Lower & Upper \\
\hline $\mathrm{H3}$ & 4.786 & 69 & .000 & .37857 & .2208 & .5364 \\
\hline
\end{tabular}

Table 11. The frequency of $\mathrm{H} 3$

Model Summary

\begin{tabular}{|c|c|c|c|c|}
\hline Model & $\mathrm{R}$ & $\mathrm{R}$ Square & Adjusted R Square & Std. Error of the Estimate \\
\hline 1 & $.853^{\mathrm{a}}$ & .728 & .724 & .34087 \\
\hline
\end{tabular}

ANOVA $^{\text {b }}$

\begin{tabular}{|c|c|c|c|c|c|c|}
\hline Model & & $\begin{array}{l}\text { Sum of } \\
\text { Squares }\end{array}$ & $\mathrm{df}$ & Mean Square & $\mathrm{F}$ & Sig. \\
\hline \multirow[t]{3}{*}{1} & Regression & 21.099 & 1 & 21.099 & 181.584 & $.000^{\mathrm{a}}$ \\
\hline & Residual & 7.901 & 68 & .116 & & \\
\hline & Total & 29.000 & 69 & & & \\
\hline
\end{tabular}

a. Predictors: (Constant), $\mathrm{H} 3$

b. Dependent Variable: DecisionMaking

Table 12. Scale defined in the questionnaire of H3

H3

\begin{tabular}{|rr|r|r|r|r|}
\hline & & Frequency & Percent & Valid Percent & $\begin{array}{c}\text { Cumulative } \\
\text { Percent }\end{array}$ \\
\hline Valid & 2.00 & 5 & 7.1 & 7.1 & 7.1 \\
& 2.50 & 5 & 7.1 & 7.1 & 14.3 \\
& 3.00 & 20 & 28.6 & 28.6 & 42.9 \\
3.50 & 18 & 25.7 & 25.7 & 68.6 \\
4.00 & 16 & 22.9 & 22.9 & 91.4 \\
4.50 & 6 & 8.6 & 8.6 & 100.0 \\
& Total & 70 & 100.0 & 100.0 & \\
\hline
\end{tabular}


Table 13. The one sample statistic of the fourth hypothesis

\begin{tabular}{|l|l|l|l|l|}
\hline \multicolumn{5}{|c|}{ One-Sample Statistics } \\
\hline H4 & N & Mean & Std. Deviation & Std. Error Mean \\
\hline
\end{tabular}

Table 14. The one sample test of the fourth hypothesis

One-Sample Test

\begin{tabular}{|l|l|l|l|l|l|l|}
\hline \multirow{2}{*}{} & \multicolumn{6}{|l|}{ Test Value $=3$} \\
\cline { 5 - 7 } & $\mathrm{t}$ & $\mathrm{df}$ & Sig.(2-tailed) & $\begin{array}{l}\text { Mean } \\
\text { Difference }\end{array}$ & Lower & Upper \\
\cline { 5 - 7 } & & & & -.45000 & -.5864 & .3136 \\
\hline H4 & -6.582 & 69 & .000 & &
\end{tabular}

Table 15. The frequency of $\mathrm{H} 4$

Model Summary

\begin{tabular}{|c|c|c|c|c|}
\hline Model & $\mathrm{R}$ & $\mathrm{R}$ Square & Adjusted R Square & Std. Error of the Estimate \\
\hline 1 & $.147^{\mathrm{a}}$ & .021 & .007 & .64600 \\
\hline \multicolumn{4}{|l}{ a. Predictors: (Constant), $\mathrm{H} 4$} \\
\hline
\end{tabular}

Table 16. Scale Defined in the questionnaire of H4

ANOVAb

\begin{tabular}{|c|c|c|c|c|c|c|}
\hline Model & & $\begin{array}{l}\text { Sum of } \\
\text { Squares }\end{array}$ & $\mathrm{df}$ & Mean Square & $\mathrm{F}$ & Sig. \\
\hline & Regression & .623 & 1 & .623 & 1.493 & $.226^{a}$ \\
\hline & Residual & 28.377 & 68 & .417 & & \\
\hline & Total & 29.000 & 69 & & & \\
\hline
\end{tabular}

a. Predictors: (Constant), $\mathrm{H} 4$

b. Dependent Variable: DecisionMaking

H4

\begin{tabular}{|ll|r|r|r|r|}
\hline & & Frequency & Percent & Valid Percent & $\begin{array}{c}\text { Cumulative } \\
\text { Percent }\end{array}$ \\
\hline Valid & 1.50 & 3 & 4.3 & 4.3 & 4.3 \\
& 2.00 & 21 & 30.0 & 30.0 & 34.3 \\
& 2.50 & 23 & 32.9 & 32.9 & 67.1 \\
3.00 & 13 & 18.6 & 18.6 & 85.7 \\
3.50 & 9 & 12.9 & 12.9 & 98.6 \\
& 4.00 & 1 & 1.4 & 1.4 & 100.0 \\
& Total & 70 & 100.0 & 100.0 & \\
\hline
\end{tabular}

Table 17. The one sample statistic of the dependent variable

One-Sample Statistics

\begin{tabular}{|l|l|l|l|l|}
\hline & $\mathrm{N}$ & Mean & Std. Deviation & Std. Error Mean \\
\hline Decision Making & 70 & 3.5000 & .64830 & .07749 \\
\hline
\end{tabular}

Table 18. The one sample test of the dependant variable

\section{One-Sample Test}

\begin{tabular}{|c|c|c|c|c|c|c|}
\hline & \multicolumn{6}{|c|}{ Test Value $=3$} \\
\hline & \multirow[b]{2}{*}{$t$} & \multirow[b]{2}{*}{ df } & \multirow[b]{2}{*}{ Sig. (2-tailed) } & \multirow{2}{*}{$\begin{array}{c}\text { Mean } \\
\text { Difference }\end{array}$} & \multicolumn{2}{|c|}{$\begin{array}{c}95 \% \text { Confidence Interval } \\
\text { of the Difference }\end{array}$} \\
\hline & & & & & Lower & Upper \\
\hline DecisionMaking & 6.453 & 69 & .000 & .50000 & .3454 & .6546 \\
\hline
\end{tabular}


Table 19. Scale defined in the questionnaire of the dependant variable

\section{DecisionMaking}

\begin{tabular}{|rr|r|r|r|r|}
\hline & & & & & Cumulative \\
& & Frequency & Percent & Valid Percent & Percent \\
\hline Valid & 2.00 & 3 & 4.3 & 4.3 & 4.3 \\
& 2.50 & 6 & 8.6 & 8.6 & 12.9 \\
& 12 & 17.1 & 17.1 & 30.0 \\
& 3.00 & 25 & 35.7 & 35.7 & 65.7 \\
& 160 & 22.9 & 22.9 & 88.6 \\
4.00 & 7 & 10.0 & 10.0 & 98.6 \\
4.50 & 1 & 1.4 & 1.4 & 100.0 \\
5.00 & 70 & 100.0 & 100.0 & \\
\hline & Total & & & & \\
\hline
\end{tabular}

Table 20. The frequency of $\mathrm{H} 1, \mathrm{H} 2, \mathrm{H} 3$ and $\mathrm{H} 4$

ANOVA $^{\mathrm{b}}$

\begin{tabular}{|ll|r|r|r|r|r|}
\hline Model & & Sum of Squares & df & Mean Square & F & Sig. \\
\hline 1 & Regression & 24.324 & 4 & 6.081 & 84.522 & $.000^{\text {a }}$ \\
& Residual & 4.676 & 65 & .072 & & \\
& Total & 29.000 & 69 & & & \\
\hline
\end{tabular}

a. Predictors: (Constant), $\mathrm{H} 4, \mathrm{H} 1, \mathrm{H} 3, \mathrm{H} 2$

b. Dependent Variable: DecisionMaking

\section{Coefficients $^{a}$}

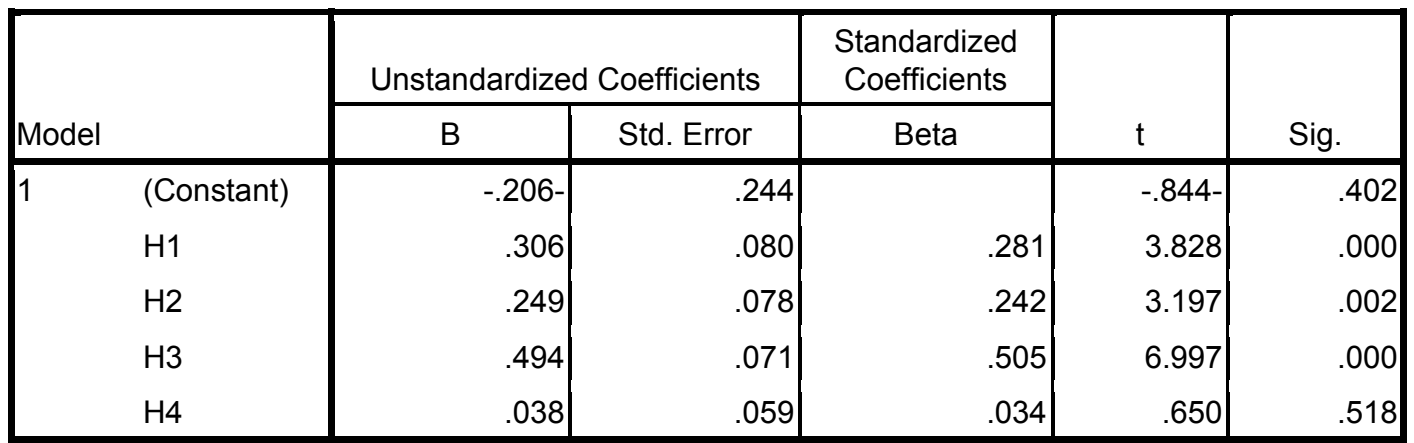

a. Dependent Variable: DecisionMaking

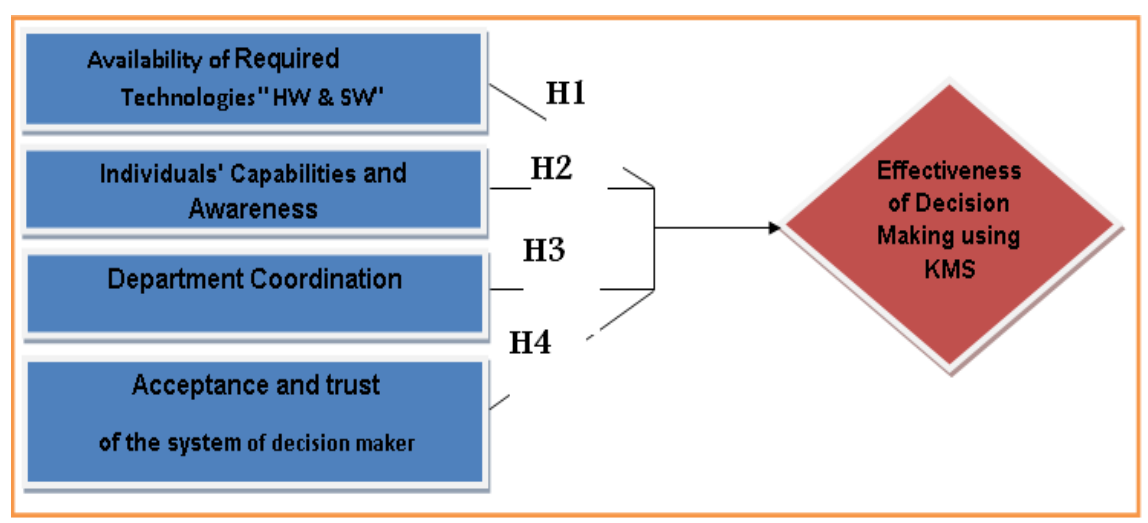

Figure 1. Research Model 